\title{
Possibility of predicting basin fog by using the maximum possible cooling amount and surveillance camera images
}

\author{
Yukitaka OHASHI ${ }^{\dagger}$, Masafumi IwASHITA, and Masashi KuSAMOTO \\ (Faculty of Informatics, Okayama University of Science, 1-1 Ridai-cho, Kita-ku, Okayama, 700-0005, Japan)
}

\begin{abstract}
We investigated the possibility of predicting fog occurring in a basin by using the maximum possible cooling amount $\left(\Delta T_{\max }\right)$ and surveillance camera images. The Miyoshi and Takahashi Basins in West Japan were chosen as our study fields. In the Miyoshi and Takahashi basins, $\Delta T_{\max }$ exceeded $10^{\circ} \mathrm{C}$ on about $80 \%$ and $70 \%$ of all the fog days, respectively. On non-fog days, $\Delta T_{\max }$ had a large peak at $4-6^{\circ} \mathrm{C}$ in both basins. This difference in $\Delta T_{\max }$ between fog and non-fog conditions provided the possibility of predicting fog using $\Delta T_{\max }$. For the Miyoshi data, discriminant analysis was conducted with the qualitative variable "fog or non-fog events" and three quantitative variables $\left(\Delta T_{\max }\right.$, dew-point depression, and wind speed) important for fog generation. A linear discriminant function for "fog or non-fog days" was derived from the result and then evaluated for fog incidences in practice. 67 of the total 82 days fog was observed were predicted as fog days. In other words, the success rate was $81.7 \%$. For non-fog days as well, the success rate was high at $81.8 \%$. The total success rate for fog and non-fog days was $81.8 \%$. Normalized coefficients of the discriminant function revealed that $\Delta T_{\max }$ had the most impact on fog incidence, followed by dew-point depression being about half as important. This result suggests that it is possible to predict a basin fog by using only two variables: $\Delta T_{\max }$ and dew-point depression.
\end{abstract}

Key words: Basin fog, Fog prediction, Maximum possible cooling amount, Surveillance camera observation.

\section{Introduction}

Fog in basin regions has been investigated worldwide by many researchers. In Japan, farm products that utilize the large diurnal change in temperature are widely developed in basin regions. This type of climate particular to basins induces abundant and high-quality crops in cultivated farmland (e.g., Chinese cabbage). However, rapid variations in the humidity and solar duration can severely damage crops.

The Miyoshi Basin in Hiroshima Prefecture, Japan, often experiences large-scale fog, especially during autumn. The landscape of the urban area in the Miyoshi Basin is shown in Fig. 1a. As shown in Fig. 1b, the

Received; May 6, 2011.

Accepted; December 1, 2011.

†Corresponding Author: ohashi@big.ous.ac.jp

${ }^{\dagger}$ Present Affiliation: Faculty of Biosphere-Geosphere Science, Okayama University of Science urban area is frequently overlaid with large-scale fog. The principal industry of Miyoshi City in the center of the basin is agriculture. Rice paddies and orchards with many kinds of fruit (e.g., grapes, pears, and apples) are cultivated here. In particular, "Pione" grapes cultivated around Miyoshi are very famous in Japan. The large diurnal temperature range characterizing the basin climate produces high-quality "Pione" grapes.

On the other hand, the long-term incidence of dense fog adversely affects farm products because of the immediate fog deposition on the forage, stem, and fruit surfaces (Jacobson, 1984; Takemoto et al., 1987; Igawa et al., 2010). The frequent incidence of highacidity fog destroys the cuticula wax layer of plant leaves and can induce damping-off disease in trees. This is because fog droplets are much smaller than those of precipitation. High-acidity fog $(\mathrm{pH} \sim 3)$ has also been observed in the Miyoshi Basin (Tanaka et al., 2000) because various acidic contents (e.g., nitrate ion, sulfate ion, and ammonium ion) are dominant within 
(a) Non-fog viewing

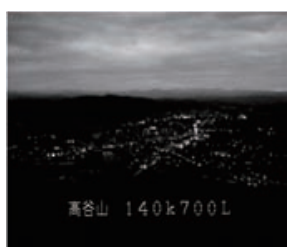

(b) Large-scaled fog viewing

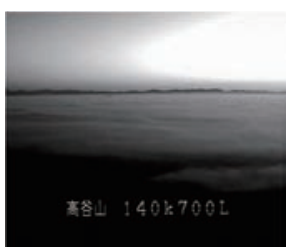

Fig. 1. Surveillance camera images from the Miyoshi Office of River and National Highway of the Ministry of Land, Infrastructure, Transport and Tourism. The Miyoshi urban area (a) under clear conditions and (b) covered with large-scale fog as viewed from the Takatani Mountain. (a) was captured on December 6, 2009 at 0637 JST while (b) on December 1, 2009 at 0645 JST. the fog droplets (Tanaka et al., 2001).

In addition, sustained dense fog has caused many issues for the inhabitants of the Miyoshi Basin, such as traffic and sanitary problems. Based on this environmental and social background, the Miyoshi Basin fog has been meteorologically investigated since the early 1980s (Miyata, 1994; Tanaka et al., 2000, 2001; Ohashi et al., 2004; Teshiba et al., 2004) . Researchers clarified many features of the basin fog as follows: (1) fog is first generated around a height of $200 \mathrm{~m}$ above ground level (AGL) and then extends vertically into the upper and lower atmospheric layers; (2) largescale fog fills up the whole Miyoshi Basin and neighboring rivers, and (3) autumn fog begins appearing

(a) Miyoshi Basin
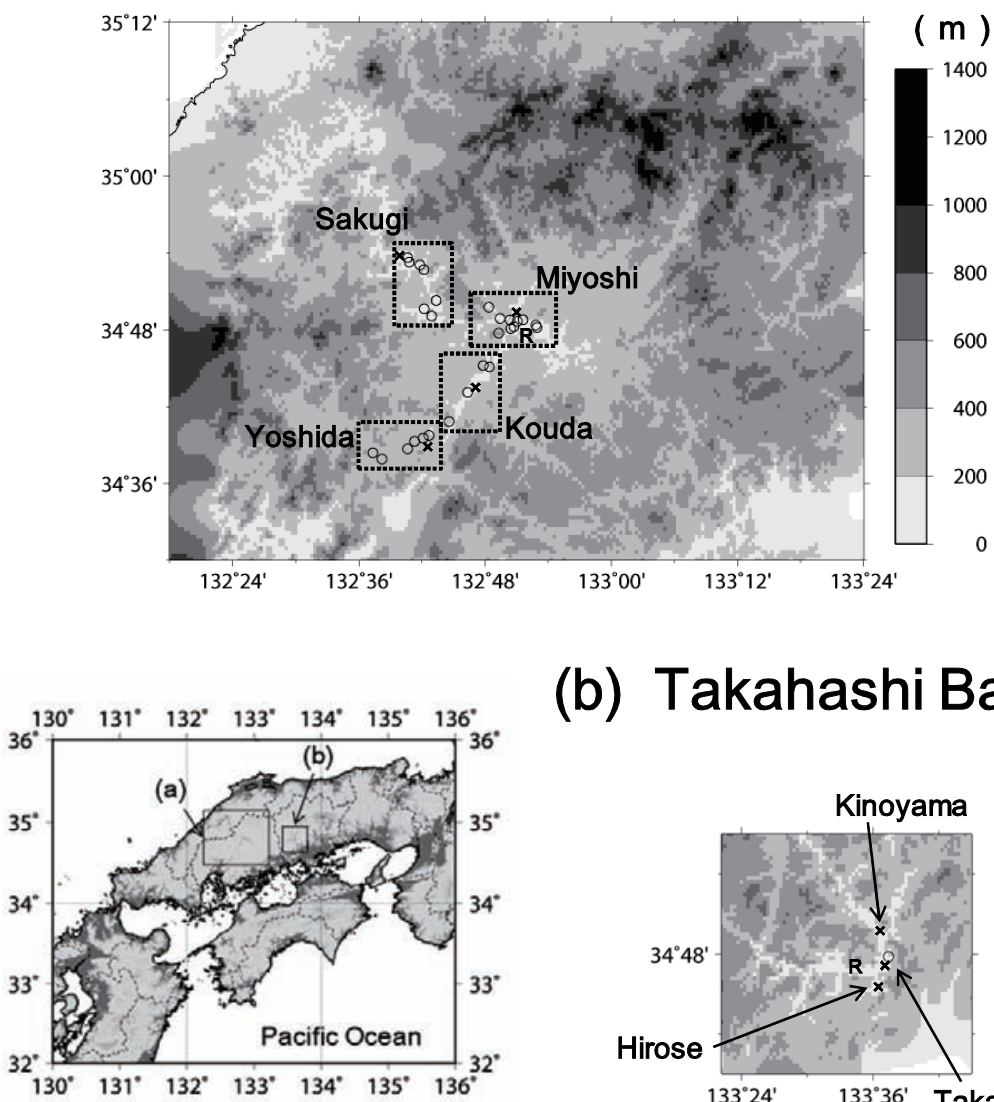

(b) Takahashi Basin

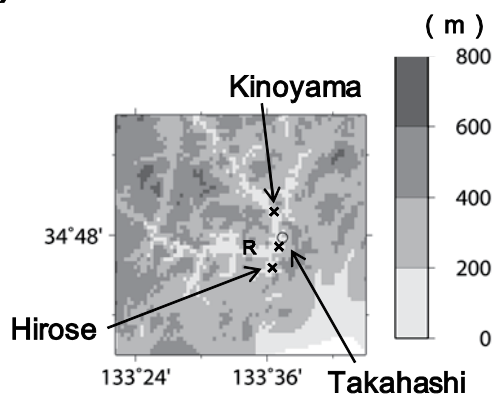

Fig. 2. Maps of the (a) Miyoshi Basin and the (b) Takahashi Basin in our study area. Open circles and crosses indicate observational locations of the surveillance camera and the maximum possible cooling amount, respectively. The symbol R represents the automated meteorological stations that are under administration of Hiroshima Prefecture in the case of (a) and Takahashi City in the case of (b). 
at 2100-2200 Japan Standard Time (JST) and completely disappears at 1100-1200 JST the following morning.

Although some meteorological conditions of the Miyoshi Basin fog have been revealed, the conditions that result in large-scale fog generation have not been determined thus far. Hence, it is difficult to predict the incidence of large-scale fog despite the fog resulting in serious agricultural and social problems in the Miyoshi region.

In general, it is very important for basin fog that the ground surface and nearby air are radiatively cooled. Kondo (1982) and Kondo and Yamazawa (1983) developed a theoretical formula representing the maximum amount of nocturnal cooling. This equation is simply based on the radiative equilibrium state between the ground surface and atmosphere at night. Since basin fog is known to be a meteorological phenomenon strongly dominated by radiative cooling effects, the above formula can be used for fog prediction. Therefore, our objective is to consider the possibility of predicting fog in the Miyoshi Basin by utilizing "the maximum possible cooling amount” that will be men- tioned later. Since the Miyoshi fog has often caused harm to residential living as indicated in the beginning of this report, fog prediction is an important subject.

Inland regions of Japan include not only broad basins but also many narrow valley-shaped basins. Thus, we also focused on the Takahashi Basin in Okayama Prefecture, which is formed as a narrow valley, in addition to the Miyoshi Basin in Hiroshima Prefecture. Figure 2 shows the locations of the Miyoshi and the Takahashi Basins.

\section{Methods}

\subsection{Study Fields}

\subsubsection{Miyoshi Basin}

The Miyoshi Basin is surrounded by the Chugoku Mountains, which have an altitude of 500-1000 m. The basin is $30-40 \mathrm{~km}$ wide, and its bottom is approximately $150 \mathrm{~m}$ above sea level. The Gouno River and its tributaries merge at the center of the basin. Fog phenomena easily appear throughout the year. In particular, autumn fog often becomes large-scale fog that fills up the basin.

Miyata (1994) stated that two types of fogs appear

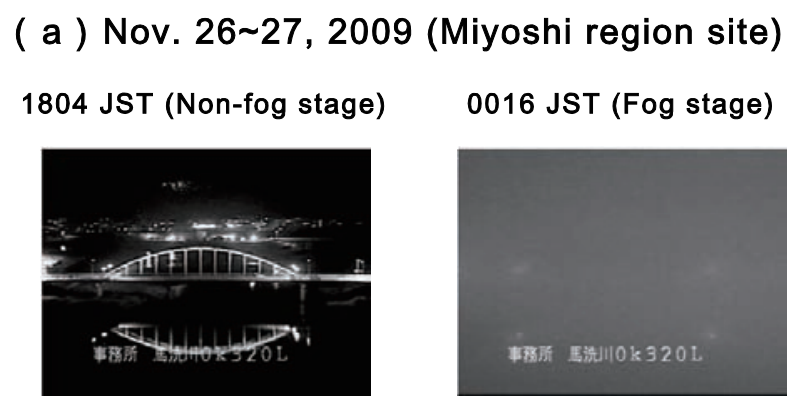

(b) Nov. 25 26, 2009 (Kouda region site)

2103 JST (Non-fog stage) 2325 JST (Fog stage)

0656 JST (Fog stage)
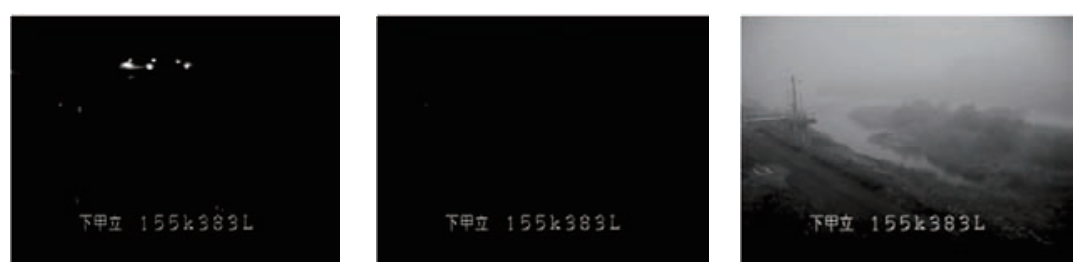

Fig. 3. Surveillance images captured at one site in the (a) Miyoshi region at 1804 JST (Non-fog stage) and 0016 JST (Fog stage) on November 26 27, 2009, and the (b) Kouda region at 2103 JST (Non-fog stage), 2325 JST (Fog stage), and 0656 JST (Fog stage) on November 25 26, 2009. 
in the Miyoshi Basin: one stays at 200-300 m AGL and does not touch the ground surface and the other grows downward to the ground surface. The latter can develop into a dense fog and does not disappear until noon.

\subsubsection{Takahashi Basin}

The Takahashi Basin is surrounded by mountains with an altitude of $500-600 \mathrm{~m}$. The basin is $2-3 \mathrm{~km}$ wide, and its bottom is approximately $100 \mathrm{~m}$ above sea level. The Takahashi and Nariwa Rivers merge at the center of this basin. Topographical features of the Takahashi Basin are quite different from those of the aforementioned Miyoshi Basin; that is, it is valleyshaped rather than having an extensive-bottom.

Katayama (2004) clarified that fogs appear earlier in the north and west regions of the basin and then flow into the basin bottom; in particular, the fog clearly flows from the west. The flow height is $200-300 \mathrm{~m}$ AGL.

\subsection{Observations}

\subsubsection{Fog Judgment Using Surveillance Camera}

It is possible to judge a fog incidence using a surveillance camera (Hautiere et al., 2006; Matsuyama et al., 2007). In general, surveillance cameras are used in the region to monitor traffic conditions, the amount of river flow, etc. We tried to use these cameras to remotely determine the time of fog appearance.

Inside the Miyoshi Basin, surveillance cameras have been set up at 28 sites administrated by the Miyoshi Office of River and National Highway, part of the Ministry of Land, Infrastructure, Transport and Tourism, for river-flow observations (open circles in Fig. 2a). On their website (http://www.cgr.mlit.go.jp/ miyoshi/), images of these sites are shown and uploaded every 10 min. Therefore, we created a Visual Basic Program to automatically download these images from the website.

In the Takahashi Basin, one surveillance camera has been set up by the Satoh Laboratory of Kibi International University (http://www.kiui.ac.jp/ t_satoh/ livecam.html). The camera location is marked in Fig. 2b. We also captured the images at 10-min intervals using computer software.

Fog is internationally defined as horizontal visibility of less than $1 \mathrm{~km}$ due to suspended liquid water in air. Target matters (e.g., street and residential lights) were previously found within a 1-km distance on the surveillance image of each camera. We then judged the invisibility of the target matter as "fog incidence" at the site.
Figure 3 indicates examples of images captured during non-fog and fog stages. As shown in the figure, easily distinguishable bridge, street, and residential lights in the non-fog stage disappear entirely in the fog stage. The above-mentioned fog incidence was regarded as a long-term evolution of fog because the appearance of fog always tended to continue for a few hours, at least during the observational period.

\subsubsection{Maximum Possible Cooling Amount}

The maximum possible cooling amount, $\Delta T_{\max }$, (Kondo, 1994; Sugawara et al., 2006) was applied for our prediction of basin fog. This physical parameter represents the maximum decrease in surface-air temperature during nighttime due to radiative cooling on flat terrain; it is often used to estimate the intensity of nighttime radiative cooling. $\Delta T_{\max }(\mathrm{K})$ can be calculated from the surface-air temperature around sunset, $T_{0}$ $(\mathrm{K})$, and the ground-surface temperature at which the radiative equilibrium state is achieved between the ground and the above atmosphere, $T_{l m t}(\mathrm{~K})$ :

$$
\Delta T_{\max }=T_{0}-T_{l m t}
$$

where $T_{l m t}$ is derived from the downward longwave radiation from the atmosphere. $L_{\downarrow}\left(\mathrm{W} \mathrm{m}^{-2}\right)$ is indicated by the following equation:

$$
T_{l m t}=\left(\frac{L_{\downarrow}}{\sigma}\right)^{1 / 4}
$$

The symbol $\sigma$ denotes the Stefan-Boltzmann constant $\left(5.67 \times 10^{-8} \mathrm{~W} \mathrm{~m}^{-2} \mathrm{~K}^{-4}\right)$. Moreover, $L_{\downarrow}$ can be estimated from the empirical equations indicated by Kondo et al. (1991) :

$$
\begin{aligned}
& L_{\downarrow}=\sigma T^{4}[1-(1-A) C] \\
& A=0.74+0.19 x+0.07 x^{2}
\end{aligned}
$$

and

$$
x=\log _{10}\left(w_{\text {top }}^{*}-w^{*}\right)
$$

Here, $T(\mathrm{~K})$ is the surface-air temperature averaged from sunset to hours just before fog, $C$ is the cloud amount, $w^{*}(\mathrm{~cm})$ is the effective water vapor amount for the depth within the basin, and $w_{\text {top }}^{*}(\mathrm{~cm})$ is the total amount of effective water vapor for the depth in the atmosphere. The value of $C$ is given as $C=1$ for clear sky, $C=0.7$ for upper cloud cover, $C=0.5$ for middle cloud cover, and $C=0.2$ for lower cloud cover (Kondo, 1994). In this study, $C$ can be immediately 
determined from the surveillance images set up on Takatani Mountain of about 500-m altitude in the Miyoshi Basin before sunset because, as can be seen in Fig. 1, the camera can capture both upper and lower cloud covers over the basin. Also, in the Takahashi Basin, the $C$ value can be specified from the surveillance image. The variables $w^{*}$ and $w_{\text {top }}^{*}$ are calculated from

$$
w^{*}=0.75 \times 10^{-4} e z
$$

and

$$
w_{\text {top }}^{*}=0.808\left(10^{0.0312 T_{d}-0.0963}\right)+0.021
$$

Here, $e(\mathrm{hPa})$ is the water vapor pressure averaged for the same period as $T, z(m)$ is the basin depth, and $T_{d}\left({ }^{\circ} \mathrm{C}\right)$ is the average dew-point temperature. Threehundred-fifty meters was adopted as the value of $z$ from the difference in representative altitudes of the surrounding mountains and basin bottom, which was estimated by using the GIS data. Although this value is slightly beyond the applied limits of $z(<200 \mathrm{~m})$ indicated by Kondo (1994), we adopted those equations in this study.

Thus, by measuring the surface-air temperature, water vapor pressure, and dew-point temperature, the $\Delta T_{\max }$ value can be calculated. Hence, we measured the air temperature, relative humidity, and dew-point temperature with small-sized temperature-humidity loggers (TSDL-HT1 and -HT2; Techno Science, Ltd.), at sites indicated by crosses in Figs. 2a and b. The measurements were carried out at a height of 1.5-2.5 m AGL where no obstacles existed nearby. The meteorological data were logged every 2 minutes.

For calculating $\Delta T_{\max }$, the hour of sunset and that just before fog were given as 1700 and 2000 JST, respectively, at all of the meteorological observation sites. The reason for this decision was to better use the meteorological data observed before the fog stage from the view point of fog prediction.

Meteorological observations for $\Delta T_{\max }$ estimation were conducted for October 16-December 12, 2009 at the Miyoshi Basin and October 16-December 15, 2009 at the Takahashi Basin. Additional $\Delta T_{\max }$ were also calculated from the data measured by public automated meteorological stations: Miyoshi R and Takahashi $\mathrm{R}$ (refer to Fig. 2).

\section{Results}

\subsection{Fog Incidence}

We divided the Miyoshi Basin into four regions: Sakugi, Miyoshi, Kouda, and Yoshida. Large-scaled fog incidences were determined from confirmations at the Takatani Mountain camera and more than two region cameras of the above-mentioned four regions. We were especially able to confirm large-scale fog covering the Miyoshi Basin using the Takatani camera, which captures almost the entire the basin. Figure 4 summarizes the earliest hours of fog incidences at the camera sites in each region. For October 19-26 and November 2024, 2009, fog incidences were inevitably unclear because the surveillance cameras went down. Hereafter, the date of a day includes the evening hours in the previous day, as shown on the horizontal axis of Fig. 4. While the fog of the Sakugi region tended to occur earliest throughout the observational period, the fog of the Miyoshi region occurred latest. On average, the Miyoshi fog appeared intensively between 2200 and 0100 JST.

In the Takahashi Basin, a fog incidence was determined using only one camera. It was difficult to completely confirm the formation of large-scale fog despite the wide-view camera. However, since the Takahashi Basin is a narrow-shaped basin, it seemed to be valid for the judgment of large-scale fog based on previous paper results (Katayama, 2004). When a fog was observed in the Takahashi Basin, it also tended to be observed in the Miyoshi Basin. The Takahashi fog mostly occurred between 2200 and 0100 JST, which is similar to the Miyoshi fog.

Large-scale fog in the Miyoshi Basin occurred for 27 days out of 43 , excluding the periods when the camera was down; this resulted in a fog probability of $63 \%$. Meanwhile, the Takahashi fog occurred for 18 days out of 56; that is, the fog probability was about $32 \%$. Therefore, the Miyoshi fog occurred about twice as often as the Takahashi fog.

\subsection{Maximum Possible Cooling Amount}

$\Delta T_{\max }$ estimated at the Sakugi, Kouda, Yoshida, Miyoshi, and Miyoshi R sites across the Miyoshi Basin are denoted in Fig. 5a. $\Delta T_{\max }$ for the Yoshida site from November 25 and for the Kouda site from December 3 were not estimated because there was a lack of meteorological data during the corresponding periods. During the observational period, $\Delta T_{\max }$ largely varied from 


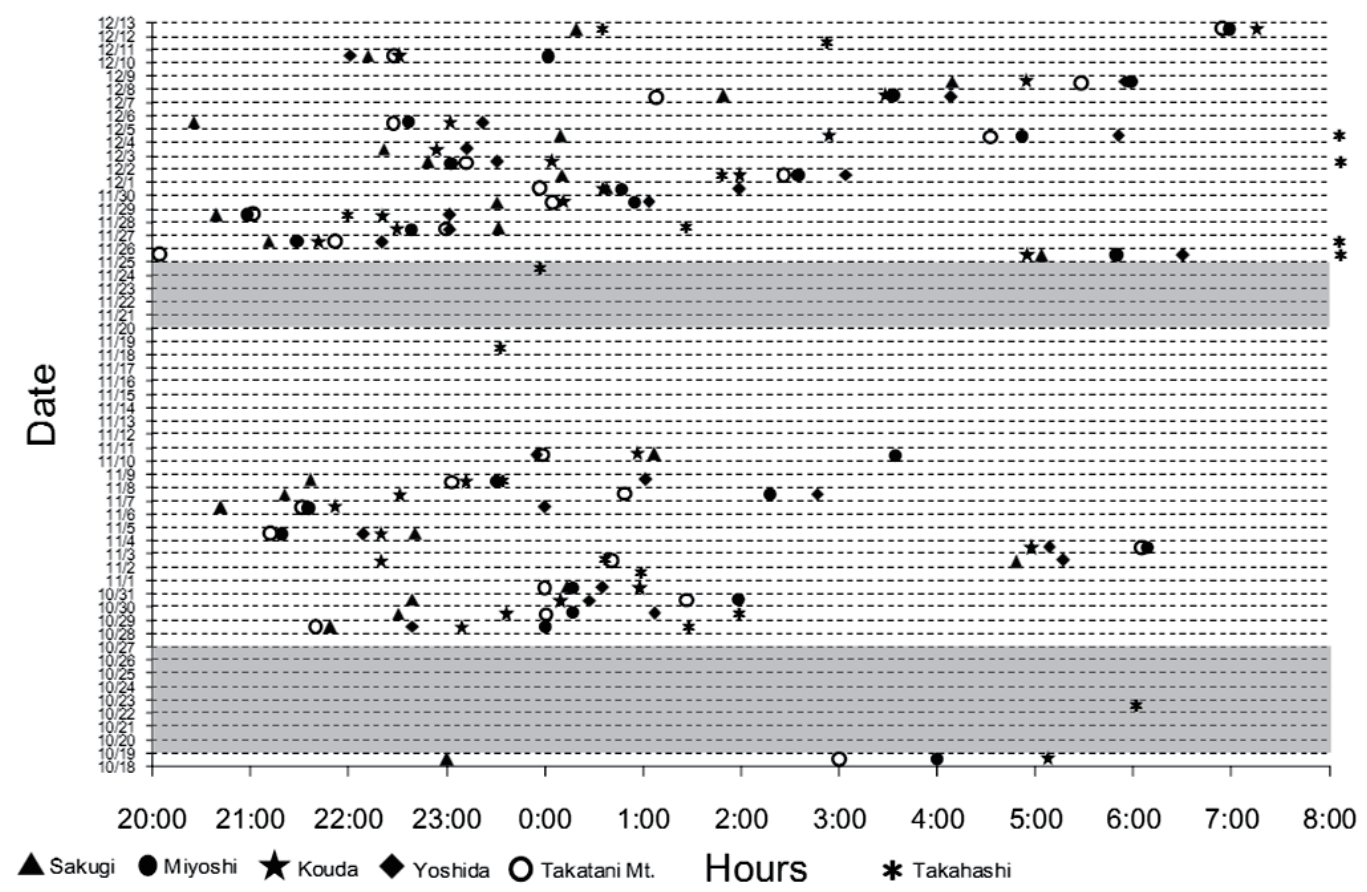

Fig. 4. Fog incidence confirmed from surveillance images. The hours when the earliest fog was observed are marked for each Sakugi $(\boldsymbol{\Delta})$, Miyoshi $(\boldsymbol{)})$, Kouda $(\star)$, Yoshida $(\bullet)$, and Takahashi $(*)$. The fog incidence hours confirmed by the camera at Mt. Takatani $(\bigcirc)$ are also included. Marks outside the right-side of graph represent unclear hours of fog incidence due to certain troubles at Takahashi. Shaded dates indicate periods when camera went down in the Miyoshi Basin.

a minimum of $4-6^{\circ} \mathrm{C}$ to a maximum of $15-18^{\circ} \mathrm{C}$. Although $\Delta T_{\max }$ estimated at Miyoshi $\mathrm{R}$ was often somewhat larger than the other sites, regional differences were not so large. Similar features appeared for the Takahashi Basin (Fig. 5b).

Figure 6 shows the frequency distributions of $\Delta T_{\max }$ estimated on each of the fog and non-fog days. Here, $\Delta T_{\max }$ was given as the average value of the observational sites across the basin. For both the Miyoshi and the Takahashi Basins, $\Delta T_{\max }$ exceeded $10^{\circ} \mathrm{C}$ for $80 \%$ and $70 \%$ of all fog days, respectively. On the other hand, $\Delta T_{\max }$ had a large peak in the range of $4-6^{\circ} \mathrm{C}$ on non-fog days in both basins. This difference in $\Delta T_{\max }$ between fog and non-fog conditions provides a possibility for predicting fog using $\Delta T_{\max }$. However, $\Delta T_{\max }$ occasionally became lower than $6^{\circ} \mathrm{C}$ even on fog days; this happened for $20 \%$ and $30 \%$ of all the fog days in Miyoshi and Takahashi, respectively. In contrast, nonfog days appearing despite $\Delta T_{\max }$ exceeding $10^{\circ} \mathrm{C}$ were recorded in both basins. These exceptions will be discussed below. 


\section{(a ) Miyoshi Basin}

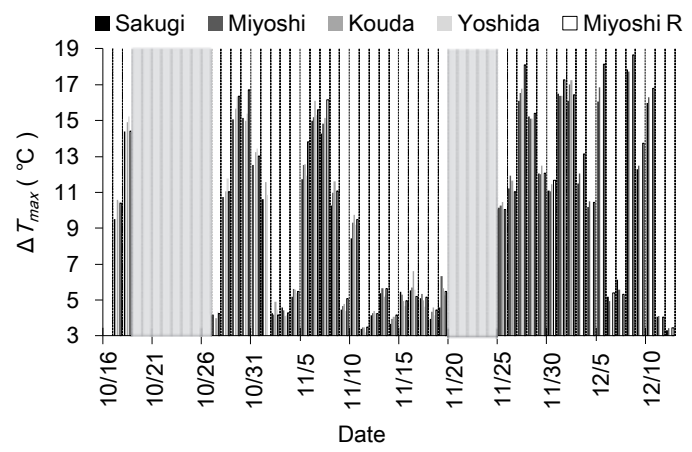

\section{(b ) Takahashi Basin}

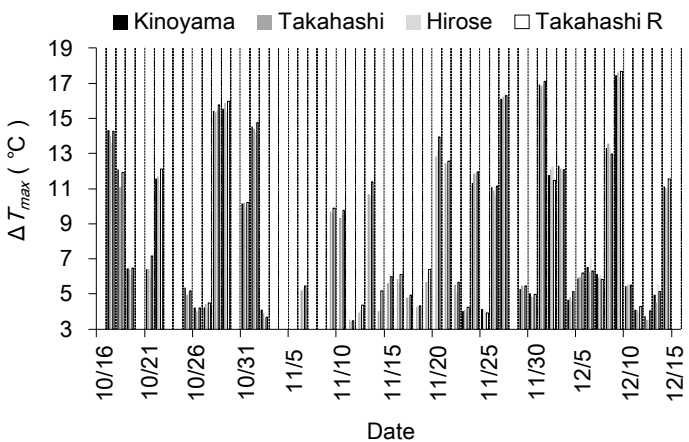

Fig. 5. Daily variations in maximum possible cooling amount $\left(\Delta T_{\max }\right)$ estimated for the (a) Miyoshi Basin and the (b) Takahashi Basin. Shaded dates in (a) correspond to periods when the camera went down. In (a), there was a lack of $\Delta T_{\max }$ at the Yoshida site from November 25, at the Kouda site from December 3.

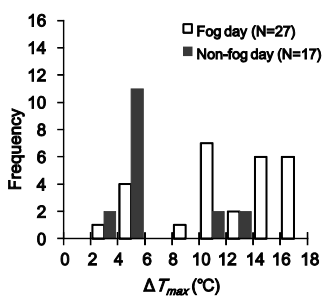

(a) Miyoshi Basin

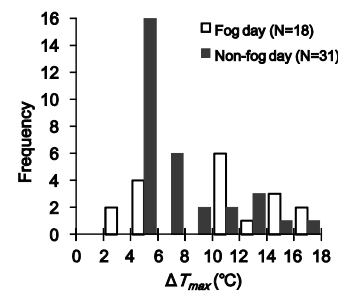

(b) Takahashi Basin

Fig. 6. Histograms of $\Delta T_{\max }$ estimated on fog and non-fog days in the (a) Miyoshi Basin and the (b) Takahashi Basin. Here, $\Delta T_{\max }$ represents the average value of the sites in each basin.

\section{Discussion}

\subsection{Exceptional Days}

As mentioned above, exceptional fog or non-fog days unexplained by $\Delta T_{\max }$ were confirmed during the observation period. This implies that the Miyoshi and Takahashi fogs are not determined solely by $\Delta T_{\max }$ in some cases. The wind and moisture conditions were also considered as meteorological variables that control fog generation. A basin fog is easy to disperse and difficult to accumulate if the mesoscale wind speed becomes larger. In addition, fog is hard to occur if the atmosphere becomes dryer. The dew-point depression, which is defined by "the air-temperature minus the dew-point temperature", represents the degree of atmospheric moisture related to a fog generation. Figure 7 shows the daily variations in dew-point depression (1700-2000 JST average just before fog hours; thick bars in the upper figure), near-surface wind speed (same average; closed circles in the upper figure), and precipitation (accumulated for 2000-0500 JST of fog hours; thin bars in the upper figure) observed in the Miyoshi Basin with $\Delta T_{\max }$ (bars in the lower figure) averaged for the four sites excluding Miyoshi R. On

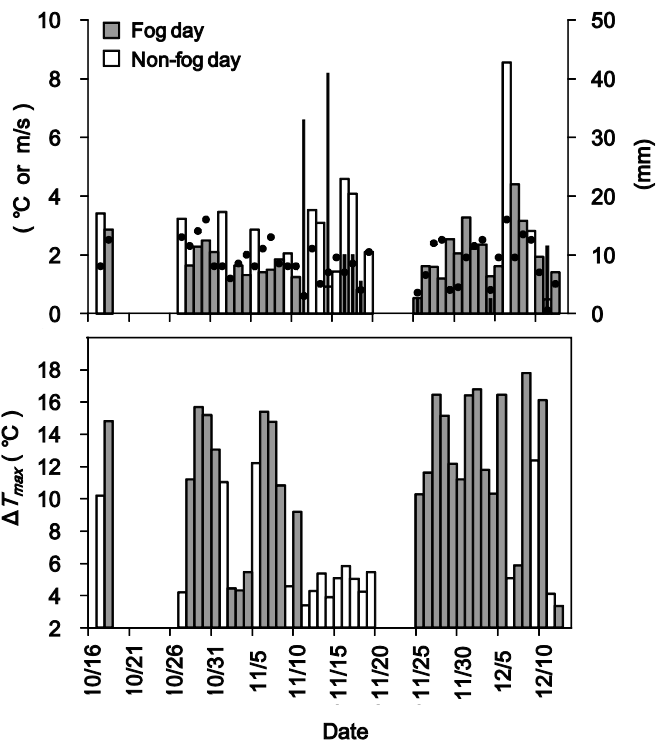

Fig. 7. Daily variations in dew-point depression (thick bars in the upper), wind speed (closed circles in the upper), precipitation (thin bars in the upper), and average $\Delta T_{\max }$ (bars in the lower) observed in the Miyoshi Basin. 
Table 1. Results of discriminant analysis for fog and non-fog days.

\begin{tabular}{lcccc}
\hline & $\Delta T_{\max }$ & Dew-point depression & Wind speed & Constant term \\
\hline Coefficients of linear discriminant & -0.2771 & +0.3463 & +0.0189 & +1.7902 \\
Normalized coefficients of linear discriminant & -1.0284 & +0.4781 & +0.0127 & - \\
& $p=0.000$ & $p=0.000$ & $p=0.931$ & - \\
\hline
\end{tabular}

fog days with smaller $\Delta T_{\max }$ such as November 2-4, dew-point depression seemed to be relatively small. On the other hand, non-fog days with larger $\Delta T_{\max }$ had large dew-point depressions such as on October 17 and November 1 and 5. Wind speeds also increased more on October 27 and December 6, both of which were non-fog days. Thus, fog generation depends on not only $\Delta T_{\max }$ but also other elements. Especially, a small dew-point depression of the atmosphere, which means moist air conditions, is considered to induce fog generation easily.

\subsection{Fog Prediction with Discriminant Analysis}

The above meteorological variables $\left(\Delta T_{\max }\right.$, dewpoint depression, and wind speed) seem to be viable for fog predictions. Hence, we tried to predict fog or non-fog days with discriminant analysis by using these three variables as explanatory independent variables. Discriminant analysis is generally applied when a response (dependent) variable and explanatory (independent) variables correspond to the qualitative data and quantitative data, respectively. Fog or non-fog incidences were defined as the qualitative data, and the three variables were defined as the quantitative data for this analysis. The total fog days of 82 and the total non-fog days of 66 at all four sites in the Miyoshi Ba-

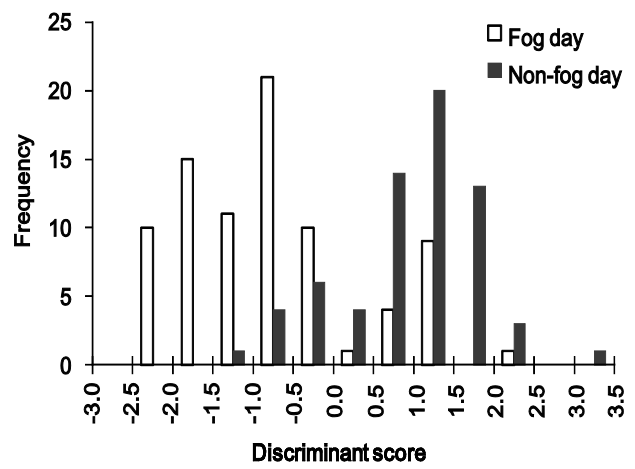

Fig. 8. Histogram of discriminant scores calculated on observed fog and non-fog days in the Miyoshi Basin. Here, the frequency indicates the total number of fog or non-fog days observed at the four observation sites. sin were used for the analysis. Hence, the number of days show the total obtained at the four observation sites. Fisher's linear discriminant function was chosen for our analysis because the homogeneity of variancecovariance matrices for the two groups (fog day and non-fog day) were confirmed by Box's $M$ test ( $p=$ 0.003).

The results of the discriminant analysis are summarized in Table 1. The discriminant function was obtained as follows:

$$
Z=-0.2771 \Delta T_{\max }+0.3463 d+0.0189 U+1.7902
$$

Here, $Z$ represents the discriminant score, $d$ is the dew-point depression $\left({ }^{\circ} \mathrm{C}\right)$, and $U$ is the surface wind speed $\left(\mathrm{m} \mathrm{s}^{-1}\right)$. The calculated value of Wilks' Lambda resulted in a statistical significance of this equation with sufficiently small $p$. A negative $Z$ value means a fog day. Figure 8 shows the histogram of the discriminant scores calculated on the observed fog and non-fog days. As shown in this figure, negative values correspond to fog days while positive values correspond to non-fog days. Peaks of the score frequency for fog and non-fog days were clearly distinct from each other, although the score distribution overlapped to some extent in the range from -1.5 to 1.5 .

Table 2 indicates the predicted results from using Eq. (8). 67 of the 82 total days when fogs were observed were predicted as fog days; this corresponded to a success rate of $81.7 \%$. For non-fog days, the success rate was also high at $81.8 \%$. The total success rate for fog and non-fog days was $81.8 \%$ based on $(67+$ 54) $/ 148$. In addition, it is important for fog predictions to not fail to be detected. Failed detections can be estimated as a ratio of 15 events to the total 148 events shown in the table, which is $10.1 \%$. Consequently, the Miyoshi fog can be predicted in practice by using Eq. (8) obtained from this study.

The normalized coefficients of the discriminant function in Table 1 revealed that $\Delta T_{\max }$ contributed most to a fog incidence, $d$ was about half as important, and $U$ had little impact. This strongly suggests that the 
Table 2. Predicted results with the discriminant function of Eq. (8).

\begin{tabular}{|c|c|c|c|c|}
\hline & \multicolumn{2}{|c|}{ Observed } & \multirow{2}{*}{$\begin{array}{l}\text { Success } \\
\text { (Error) rate }\end{array}$} \\
\hline & & $\begin{array}{c}\text { Fog day } \\
\text { (82) }\end{array}$ & $\begin{array}{l}\text { Non-fog } \\
\text { day (66) }\end{array}$ & \\
\hline \multirow{2}{*}{ Predicted } & Fog day & 67 & 12 & $81.7(18.2) \%$ \\
\hline & Non-fog day & 15 & 54 & 81.8 (18.3) \% \\
\hline
\end{tabular}

fog incidence can be predicted by using both of the maximum possible cooling amount $\left(\Delta T_{\max }\right)$ and dewpoint depression $(d)$.

\section{Conclusions}

We explored the possibility of predicting fog in basins using meteorological observations and estimating the maximum possible cooling amount $\left(\Delta T_{\max }\right)$.

In this study, surveillance camera images were utilized to confirm a fog incidence. The Miyoshi and Takahashi Basins in West Japan during autumn 2009 were chosen as the fields of our study.

For Miyoshi and Takahashi, $\Delta T_{\max }$ exceeded $10^{\circ} \mathrm{C}$ for about $80 \%$ and $70 \%$ of all fog days (27 days at Miyoshi and 18 days at Takahashi), respectively. On non-fog days, $\Delta T_{\max }$ had a large peak in the range of 4$6^{\circ} \mathrm{C}$ in both basins. This difference in $\Delta T_{\max }$ between fog and non-fog conditions supported the possibility of predicting fog by using $\Delta T_{\max }$.

For the Miyoshi data, discriminant analysis was conducted with the qualitative variable "fog or non-fog days" and three quantitative variables $\left(\Delta T_{\max }\right.$, dewpoint depression, and wind speed) that are important for fog generation. A linear discriminant function for “fog or non-fog days” was derived from the result and then evaluated for fog incidences in practice. 67 of the 82 total days fog was observed were predicted as fog days. In other words, the success rate was $81.7 \%$. For non-fog days, the success rate was also high at $81.8 \%$. As a result, the total hit rate for fog and non-fog days was $81.8 \%$.

Normalized coefficients of the discriminant function revealed that $\Delta T_{\max }$ contributed most to the incidence of fog, followed by dew-point depression being about half as important. This result suggests that a fog incidence can be predicted by using both $\Delta T_{\max }$ and dewpoint depression.

The above prediction method will need to be evaluated for various other basins. In addition, more longterm observations carried out over several years will provide a robust validation of this study. The accumu- lation of research has high potential for the realization of accurately predicting fog.

\section{Acknowledgments}

We thank all associated public organizations of Hiroshima and Okayama prefectures for their great assistance with our temperature measurements. We greatly appreciate Dr. Y. Shigeta (then Okayama University, Japan) for his help in our observations.

\section{References}

Hautiere, N., Tarel, J. -P., Lavenant, J., and Aubert, D., 2006: Automatic fog detection and estimation of visibility distance through use of an onboard camera. Mach. Vis. Appl., 17, 8-20.

Igawa, M., Shigihara, A., Goto, S., and Nanzai, B., 2010: Acid fog deposition and the declining forest in Tanzawa mountains, Japan. 5th International Conference on Fog, Fog Collection and Dew. (available at http://meetingorganizer.copernicus.org/ FOGDEW2010/FOGDEW2010-10.pdf).

Jacobson, J. S., 1984: Effects of acidic aerosol, fog, mist and rain on crops and trees. Phil. Trans. R. Soc. Lond., B305, 327-338.

Katayama, H., 2004: Observational study on basin fog, temperature and humidity in Takahashi City. Master Thesis, Okayama University Graduate School of Natrural Science and Technology, 33 pp.

Kondo, J., 1982: Preliminary theoretical study on nocturnal cooling over complex terrain. Tenki, 29, 935949 (in Japanese).

Kondo, J., 1994: Mizukankyou no kisyougaku. Asakura syoten, Tokyo, 350 pp. (in Japanese).

Kondo, J., and Yamazawa, H., 1983: Nocturnal radiational cooling of the earth's surface with the snowcover, and the extreme minimum air-temperature over Japan. Tenki, 30, 295-302 (in Japanese).

Kondo, J., Nakamura, T., and Yamazaki, T., 1991: Estimation of the solar and downward atmospheric radiation. Tenki, 38, 41-48 (in Japanese).

Matsuyama, Y., Miyoshi, T., Matsuda, Y., Kajiya, Y., 
and Matsuzawa, M., 2007: Usefulness of fog forecast provision for a mountain pass. Proceedings of 6th ITS Symposium, 381-386 (in Japanese with English abstract).

Miyata, K., 1994: Miyoshibonchi no kiri no kenkyu. Keisuisya, Hiroshima, Japan, 255 pp. (in Japanese).

Ohashi, Y., Terao, T., Miyata, K., Tanaka, M., Horiguchi, M., and Hayashi, T., 2004: Relationship between generation of basin fog and moisture transport by local circulations-Numerical simulations of local circulations developed over Miyoshi Basin-. Tenki, 51, 509-523 (in Japanese).

Sugawara, H., Narita, K., Mikami, T., Honjo, T., and Ishii, K., 2006: Cool island intensity in a large urban green: seasonal variation and relationship to atmospheric condition. Tenki, 53, 393-404 (in Japanese with English abstract).

Takemoto, B. K., Olszyk, D. M., Johnson, A. G., and Parada, C. R., 1988: Yield responses of field-grown crops to acidic fog and ambient ozone. J. Environ. Qual., 17, 192-197.

Tanaka, M., Miyata, K., Maitani, T., Hayashi, T., Itoh, Y., Horiguchi, M., Terao, T., Iwata, T., and Ohashi, Y., 2000: Intensive fog observations over the Miyoshi basin. Annu. Disas. Prev. Res. Inst., Kyoto Univ., 43 B-1, 185-209 (in Japanese with English abstract).

Tanaka, M., Miyata, K., Maitani, T., Hayashi, T., Itoh, Y., Horiguchi, M., Terao, T., Iwata, T., Ohashi, Y., Oohara, M., Miyashita, K., Hashiguchi, H., and Teshiba, M., 2001: Intensive fog observations over the Miyoshi basin (Part 2). Annu. Disas. Prev. Res. Inst., Kyoto Univ., 44 B-1, 37-69 (in Japanese with English abstract).

Teshiba, M., Hashiguchi, H., Uematsu, A., Tanaka, H., Ohmori, Y., and Fukao, S., 2004: Fog observations with a millimeter-wave scanning radar at Miyoshi basin, Japan. Earth Planets Space, 56, 259-268. 